\title{
Effects of PCB Substrate Surface Finish, Flux, and Phosphorus Content on Ionic Contamination
}

\author{
M. Bacior, N. Sobczak, A. Siewiorek, A. Kudyba, M. Homa, R. Nowak, M. Dziula, and S. Masłoń
}

(Submitted September 25, 2014; published online December 20, 2014)

\begin{abstract}
The ionic contamination on printed circuit boards (PCB) having different surface finishes was examined using ionograph. The study was performed at the RT on three types of PCBs covered with: (i) hot air solder leveling (HASL LF), (ii) electroless nickel immersion gold (ENIG), and (iii) organic surface protectant (OSP), all on Cu substrates, as well as two types of fluxes, namely EF2202 and RF800. In the group of boards without soldered components, the lowest average value of contamination was for the ENIG $18 \mu \mathrm{m}$ surface $\left(0.01 \mu \mathrm{g} \mathrm{NaCl} / \mathrm{cm}^{2}\right.$ ). Boards with soldered components were more contaminated (from $0.29 \mu \mathrm{g}$ $\mathrm{NaCl} / \mathrm{cm}^{2}$ for the HASL LF $18 \mu \mathrm{m}$ surface). After spraying boards with fluxing agents, the values of contaminants were the highest. The influence of phosphorus content in Ni-P layer of ENIG finish on ionic contamination was examined. In the group of PCBs with Au coating, the smallest amount of surface contaminants $\left(0.32 \mu \mathrm{g} \mathrm{NaCl} / \mathrm{cm}^{2}\right)$ was for $\mathrm{Ni-2-5 \%}$ P layer. PCBs with $\mathrm{Ni}-11 \% \mathrm{P}$ layer were higher contaminated $\left(0.47 \mu \mathrm{g} \mathrm{NaCl} / \mathrm{cm}^{2}\right)$, and another with $\mathrm{Ni}-8 \% \mathrm{P}$ layer had $0.81 \mu \mathrm{g} \mathrm{NaCl} / \mathrm{cm}^{2}$. PCBs without Au coating, had the lowest contamination $\left(0.48 \mu \mathrm{g} \mathrm{NaCl} / \mathrm{cm}^{2}\right)$ at phosphorous content equal $11 \% \mathrm{P}$. Higher contamination $\left(0.67 \mu \mathrm{g} \mathrm{NaCl} / \mathrm{cm}^{2}\right)$ was at $2-5 \% \mathrm{P}$, up to $1.98 \mu \mathrm{g} \mathrm{NaCl} / \mathrm{cm}^{2}$ for $8 \%$ of P. Boards with Au finish have lower value of contamination than identical boards without Au layer thus contributing to better reliability of electronic assemblies, since its failures due to current leakage and corrosion can be caused by contaminants.
\end{abstract}

Keywords ENIG, HASL, ionic contamination, OSP, PCB

\section{Introduction}

The printed circuit boards (PCB) are the insulation boards with a suitable thickness and stiffness that are commonly used in many electronic devices, from consumer electronics up to specialized equipment. PCBs are covered with numerous conductive tracks and soldering fields, and in multi-layer boards, the connection track is three-dimensional, combining elements of individual layers. Conductive materials are usually copper or nickel with phosphorus additive (about 9 wt.\%) (Ref 1). Different protective finishes (HASL LF, ENIG, OSP, etc.) are deposited on the soldering fields and conductive tracks in order to prevent the oxidation process of the conductive material $(\mathrm{Cu}$ or $\mathrm{Ni}-\mathrm{P})$ in the period between the board formation and the soldering process of electronic components on the board. The protective finishes affect the quality of the soldered components because interfacial intermetallic compounds (IMCs) generated due to interaction between liquid solder and protective coating in soldering process affect the electrical, mechanical characteristics, and the reliability of a solder joints

M.Bacior, University of Agriculture in Krakow - Agriculture and Economics, Al. Mickiewicza 21, 31-120 Kraków, Poland; N.Sobczak, A.Siewiorek, A.Kudyba, M.Homa, and R.Nowak, Foundry Research Institute - Center for High-Temperature Studies, Kraków, Poland; and M.Dziula and S.Masłoń, Fideltronik Imel, Sucha Beskidzka, Poland. Contact e-mail: m.bacior@ur.krakow.pl.
(Ref 2). PCB surface finishes have two main functions: firstly to protect the exposed copper circuit, and secondly to provide a solderable surface during soldering the components to the board. Among different finishes of solder mask over bare copper, there are three types, which are mostly used in practice: (i) hot air solder leveling (HASL LF), (ii) electroless nickel immersion gold (ENIG), and (iii) organic surface protectant (OSP).

During HASL LF process, the lead-free solder finish is deposited on $\mathrm{Cu}$ substrate. The thickness of this type of finish is about 1.3-35 $\mu \mathrm{m}$, and its advantages are low cost, good shelf life, as well as great solderability, while its disadvantages are non-uniformity of the finish, low thermal shock resistance, and the formation of brittle IMCs at the interface.

ENIG finish is deposited on $\mathrm{Cu}$ substrate and it is composed of two layers, i.e., a gold layer (thickness from 0.05 to $0.25 \mu \mathrm{m}$ ) over nickel containing a phosphorous layer (thickness from 1 to $8 \mu \mathrm{m})$. The benefits of this kind of finish are long-term experience in practice, good corrosion resistance and great solderability, as well as shelf life of about one year. However, the disadvantages of the ENIG surface finish are higher production cost and a two-stage process. Moreover, the uncontrolled quality of ENIG coating may reduce the solder joint reliability, because of such structural defects as a "Black Pad" (Ref 3, 4).

OSP finish is deposited on $\mathrm{Cu}$ substrate, and its typical thickness ranges from 0.2 to $0.5 \mu \mathrm{m}$. This kind of surface finish has a 1-year shelf life and can handle multiple heat cycles, but its main disadvantage is difficult inspection of the final product (Ref 5).

An influence of surface finishes and fluxing agent on the wettability and solderability of PCBs with $\mathrm{Pb}$-free solders are widely discussed in the literature. However, there is no 
information how these factors affect ionic contamination of PCBs. Reference 5 and 6 report the study on the effects of type of surface finish and flux on solderability of the SAC305 leadfree alloy performed at a temperature of $260{ }^{\circ} \mathrm{C}$. Three types of PCBs were tested: (i) HASL LF, (ii) ENIG, and (iii) OSP, all on $\mathrm{Cu}$ substrates and two types of fluxes: EF2202 and RF800. The results showed that the shortest wetting time was for the OSP finish, from $t_{0}=0.6 \mathrm{~s}$ with EF2202 flux to $t_{0}=0.98 \mathrm{~s}$ with RF800 flux. The ENIG finish showed the longest wetting time from $t_{0}=1.36 \mathrm{~s}(\mathrm{EF} 2202)$ to $t_{0}=1.55 \mathrm{~s}$ (RF800). The lowest $\theta$ of $45^{\circ}$ was formed on HASL LF (EF2202), while the highest $\theta$ of $63^{\circ}$ was noted on the OSP finish (RF800).

In the increased moisture conditions, contaminants present in the electronic assemblies may lead to increased electrical leakage, chemical and electrochemical corrosion of galvanic finishes and formation of dendrites, which leads to damage of electronic products.

There are different values of allowable contamination, which depend on the method of measurement. For measurements with the help of ionograph, this value is $3.1 \mu \mathrm{g} \mathrm{NaCl} /$ $\mathrm{cm}^{2}$ (Ref 7, 8), according to other sources (e.g. Ref 9, 10), the contamination of $\mathrm{PCB}$ and electronic components included in the installation should not exceed $0.8 \mu \mathrm{g} \mathrm{NaCl} / \mathrm{cm}^{2}$.

There are three types of contaminants such as ionic, nonionic, and others, among which ionic contaminants are the most crucial, because under the influence of water, they decompose into ions and conduct electricity ( $\operatorname{Ref} 1,2,7)$. The ionic contaminants on the substrate (mainly chlorides and bromides) lead to corrosion because of the potential difference between the metals, which have contact due to moisture, and the current flow associated with the presence of ions.

The processes, which involve fluxing agents, such as applying the metal finishes on the PCBs with the HASL method, as well as soldering, are the largest sources of contaminants. In soldering, the source of ions can be the products of the fluxing agent thermal degradation or decomposition, and at the higher temperature of soldering with leadfree alloys - products of the reaction between fluxing agents and oxides on the ends of soldered components and solder.

In the present work, the influence of the type of flux and PCB surface finish (HASL LF, ENIG, and OSP), as well as phosphorous content in ENIG finish on ionic contamination was examined.

\section{Materials and Testing}

Investigated materials were PCBs produced by ELTAR (Poland) with three types of finish, namely: (i) HASL LF (leadfree), (ii) ENIG; and (iii) OSP. The thickness of the PCB finish was 18 and $35 \mu \mathrm{m}$, while the surface of tested boards was $143 \mathrm{~cm}^{2}$ (Fig. 1a).

The level of surface ionic contamination of each type of PCB finish both in delivery state (before soldering and with soldered components after soldering) was investigated. Next, the surfaces of PCBs in delivery state were treated with a flux, and the level of the present contamination was re-examined.

Two commercial fluxes EF2202, and RF800 were used in this study. EF2202 consists of a proprietary mixture of organic activators, which deliver excellent wetting. It is a VOC-free, halide-free, rosin/resin-free, and low solid no-clean flux which demonstrates the highest activity of any VOC-free Bellcore

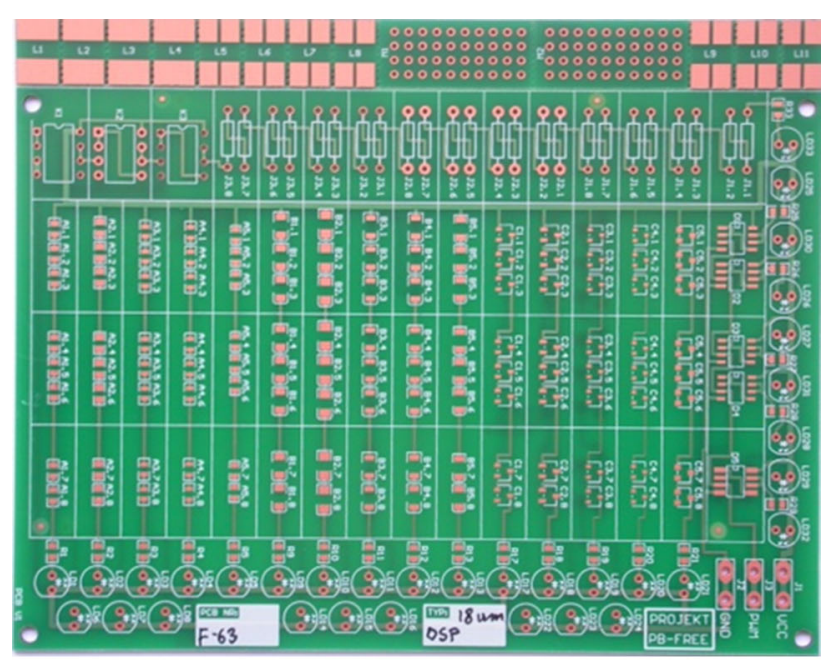

(a)

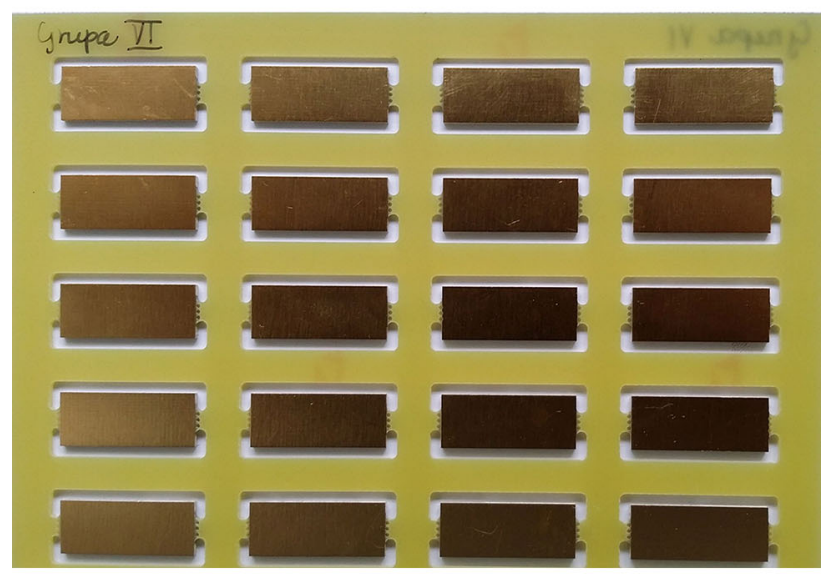

(b)

Fig. 1 Examples of PCBs with different surface finishes: (a) OSP $18 \mu \mathrm{m}$ (without soldered components); (b) board with $\mathrm{Au} / \mathrm{Ni}-2-5 \% \mathrm{P}$ finish

compliant flux for defect-free soldering. RF800 provides the broadest process window for a no-clean flux with less than $5 \%$ solid content and is designed to provide excellent soldering results (low defects rates), even when the surfaces to be soldered (component leads and pads) are not highly solderable. RF800 works particularly well with bare copper boards protected with organic or rosin/resin coatings and with tinlead-coated PCBs (Ref 11).

In the second stage of the study, the influence of phosphorous content in Ni-P layer on surface contaminants of board was investigated. The surface of each tested board was $143 \mathrm{~cm}^{2}$. The substrates were made from $\mathrm{Cu}(99.9 \%)$ on which seven types of coating were deposited by commercial process (ELTAR, Poland):

(1) Ag coating with a standard thickness (as that used in PCBs);

(2) Ni-2-5\%P (heafter in wt.\%) finish (deposited in middling phosphorus bath, usually used to Ni-P coating on PCB) without Au layer;

(3) $\mathrm{Au} / \mathrm{Ni}-2-5 \% \mathrm{P}$ finish, additionally covered with a thin protect layer of gold $(0.2 \mu \mathrm{m}$ thickness $)$. The thickness 



Fig. 2 Ionic contamination expressed as $\mu \mathrm{g} \mathrm{NaCl} / \mathrm{cm}^{2}$ for different PCB finishes as a function of time. (a) OSP in delivery state (b) OSP with soldered components (c) Ni-8\%P; (d) $\mathrm{Au} / \mathrm{Ni}-8 \% \mathrm{P}$

of the $\mathrm{Au}$ and Ni-P layers, as well as the technology of its deposition is identical as in case of ENIG surface finishes in PCBs;

(4) Ni-8\%P finish (middling phosphorus bath, usually used to Ni-P coating on $\mathrm{PCB}$, without $\mathrm{Au}$ layer);

(5) $\mathrm{Au} / \mathrm{Ni}-8 \% \mathrm{P}$ finish, additionally covered with a thin protect layer of gold $(0.2 \mu \mathrm{m}$ thickness $)$. The thickness of the Au and Ni-P layers, as well as the technology of its deposition is identical as in case of ENIG surface finishes in PCBs;

(6) Ni-11\%P finish (strongly phosphorus bath, not used in practice on PCBs), without Au layer;

(7) $\mathrm{Au} / \mathrm{Ni}-11 \% \mathrm{P}$ finish, additionally covered with a thin protect layer of $\mathrm{Au}(0.2 \mu \mathrm{m}$ thickness $)$. This kind of layer is not used in PCBs.

The cleanliness of the PCBs was examined on the Ionograph Contamino CT100 (Métronélec, France). This device allows easy and accurate measurements of the ion contamination level in PCBs (Ref 12). The ultra-pure isopropanol and deionized water (2-propanol) solutions were used for the extraction of deposits on PCBs; since alcohol dissolves non-polar components, and water dissolves the polar rest of the deposit (Ref 13). Before measurements, $5 \mathrm{~L}$ of $50 \%$ ultra-clear isopropanol and deionized water solution had been prepared. At the beginning of each measurement series, the temperature of the solution, as well as its density was measured, and with the help of the calibration graph of the relation between the solution percentage concentration and the density at the given temperature, it was examined whether the concentration of the solution is between 45 and 55\%. Then, before each measurement, automatic regeneration of the solution had been made.

\section{Results and Discussion}

Typical acquired ionic contamination curves as a function of time $t$ of the PCB surfaces are shown in Fig. 2.

The obtained results show that PCBs in delivery state (without soldered components) had lower average value of contaminants than those with soldered components (preliminary studies on this issue are reported in Ref 14). In this group of boards, the lowest average value of contamination, namely $0.01 \mu \mathrm{g} \mathrm{NaCl} / \mathrm{cm}^{2}$, was obtained for the ENIG finish with $18 \mu \mathrm{m}$ thick $\mathrm{Cu}$ layer, while for the HASL LF of the same thickness the value of the surface contamination was the highest $\left(0.15 \mu \mathrm{g} \mathrm{NaCl} / \mathrm{cm}^{2}\right)$.

PCBs with soldered components have higher values of contamination and in this group of boards, the least contaminated boards of $0.29 \mu \mathrm{g} \mathrm{NaCl} / \mathrm{cm}^{2}$ were noted for HASL LF of $18 \mu \mathrm{m}$ thickness. The most contaminated PCBs had an organic OSP finish of a copper layer of $18 \mu \mathrm{m}$ thickness showing $0.44 \mu \mathrm{g} \mathrm{NaCl} / \mathrm{cm}^{2}$ (Fig. 3a).

Contamination of boards treated with flux was higher (Fig. 3b). EF2202 contaminates the surface of PCBs to a lesser extent than RF800. For the group of PCBs treated with EF2202, the lowest amount of contamination of $0.55 \mu \mathrm{g} \mathrm{NaCl} / \mathrm{cm}^{2}$ was 

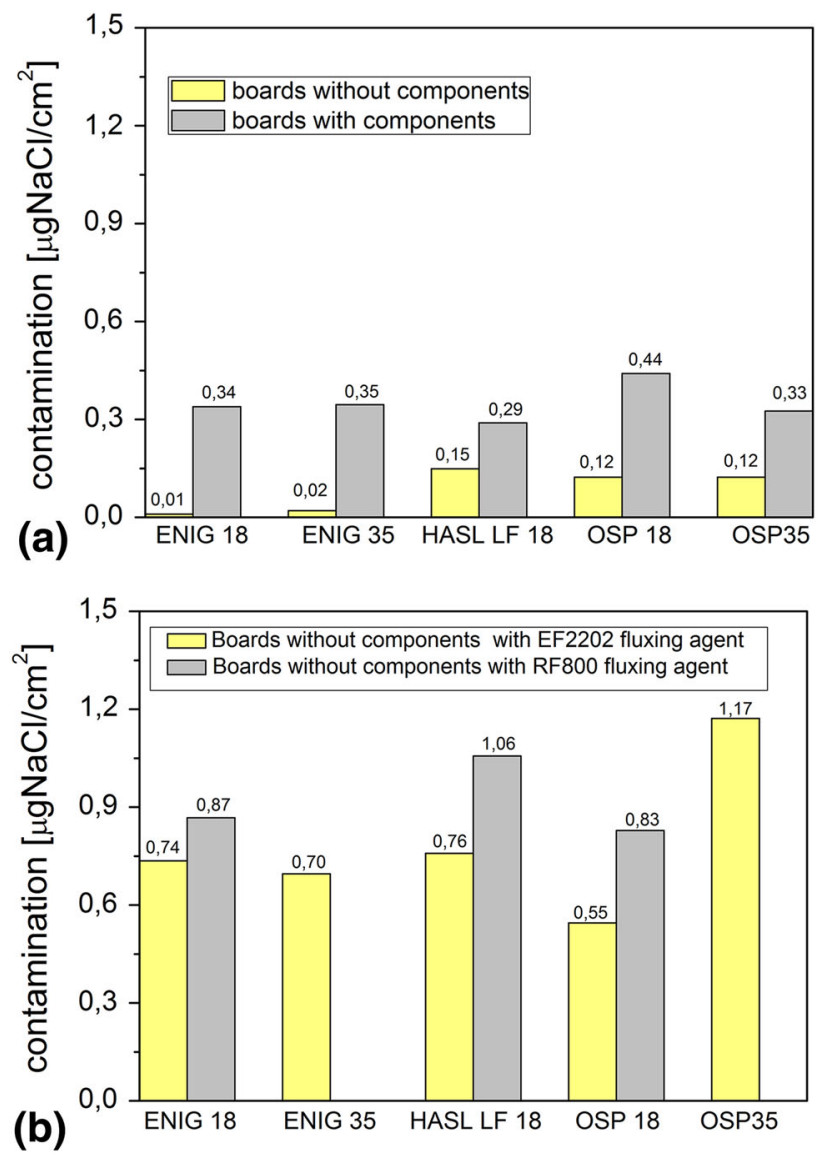

Fig. 3 Comparison of ionic contamination PCBs with different finishes (in $\mu \mathrm{g} \mathrm{NaCl} / \mathrm{cm}^{2}$ ): (a) PCBs in delivery state (without soldered components) and those with soldered components; (b) PCBs without components after treatment with flux EF2202 and RF800

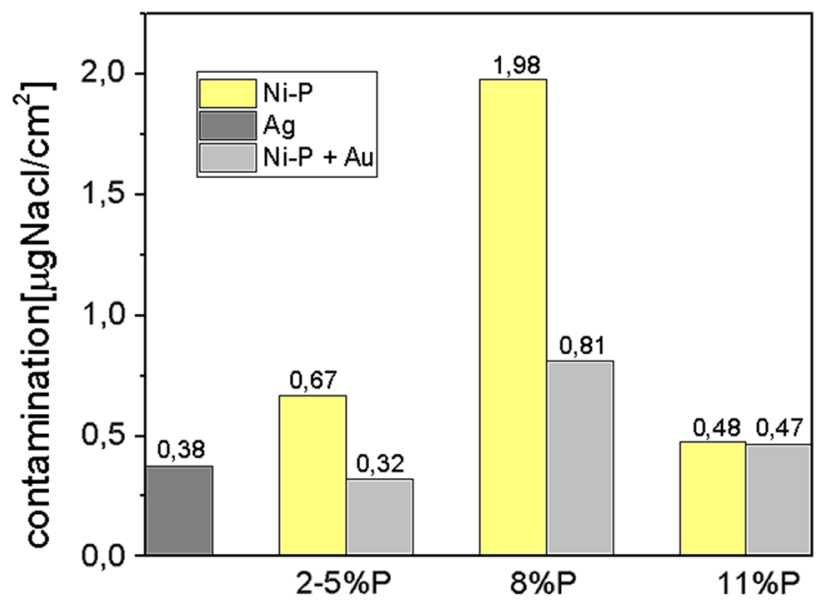

Fig. 4 Effect of phosphorous content in Ni-P finish and deposition of additional $\mathrm{Au}$ layer on Ni-P on ionic contamination of PCBs expressed as $\mu \mathrm{g} \mathrm{NaCl} / \mathrm{cm}^{2}$

noted for OSP finish while the highest - boards with the organic coating showing $1.17 \mu \mathrm{g} \mathrm{NaCl} / \mathrm{cm}^{2}$ in case of PCB with $35 \mu \mathrm{m}$ thick $\mathrm{Cu}$ layer. Surface contamination of the PCBs treated with $\mathrm{RF} 800$ has the contamination values in the range between $0.83 \mu \mathrm{g} \mathrm{NaCl} / \mathrm{cm}^{2}$ for OSP up to $1.06 \mu \mathrm{g} \mathrm{NaCl} / \mathrm{cm}^{2}$ for boards with HASL LF.
Comparison of determined values of ionic contamination for PCBs with Ni-P finish having different phosphorous contents, as well as for those with additional Au layer (ENIG) is shown in Fig. 4.

PCBs with Ni-P finish with additional Au coating, deposited on Ni-P finish show lower value of contamination than those without Au layer. Phosphorus content in the surface finishes has serious influence to ionic contamination, mainly in the group of PCBs without $\mathrm{Au}$ layer. In this group, the lowest value of contamination was obtained for $\mathrm{Ni}-11 \% \mathrm{P}$ coating: $0.48 \mu \mathrm{g}$ $\mathrm{NaCl} / \mathrm{cm}^{2}$. Surface of $\mathrm{Ni}-2-5 \% \mathrm{P}$ was more contaminated $\left(0.67 \mu \mathrm{g} \mathrm{NaCl} / \mathrm{cm}^{2}\right)$, and the most contaminated was boards with Ni-8\%P surface $\left(1.98 \mu \mathrm{g} \mathrm{NaCl} / \mathrm{cm}^{2}\right)$. PCBs covered by $\mathrm{Au}$ layer have smaller amounts of contaminants: from $0.32 \mu \mathrm{g}$ $\mathrm{NaCl} / \mathrm{cm}^{2}$ for $\mathrm{Au} / \mathrm{Ni}-2-5 \% \mathrm{P}$ layer, up to $0.81 \mu \mathrm{g} \mathrm{NaCl} / \mathrm{cm}^{2}$ for $\mathrm{Au} / \mathrm{Ni}-8 \% \mathrm{P}$ layer. $\mathrm{Ag}$ in Fig. 4 means $\mathrm{Ag}$ coating with a standard thickness (as that used in PCBs).

\section{Conclusions}

The ionic contamination measurements on PCBs having three different surface finishes (HASL LF, ENIG, and OSP) on $\mathrm{Cu}$ substrates and using two types of fluxes (EF2202 and RF800), as well as on the PCBs with different phosphorous contents in Ni-P and $\mathrm{Au} / \mathrm{Ni}-\mathrm{P}$ layer are evidenced as follows:

(1) The presence of soldered components on PCBs has a strong effect on their ionic contamination. In the group of boards with soldered components, the level of surface contaminants was higher than that for PCBs in delivery state (without soldered components).

(2) After spraying PCBs without soldered components with the EF2202 fluxing agent, the surface has higher values of contaminants, compared to those for the boards with the components in the delivery state. RF800 fluxing agent more contaminates the surface of PCBs, than EF2202.

(3) The tested PCBs meet the requirements of the MILP-28809 standard for ionograph tests, because obtained values of ionic contamination do not exceed $3.1 \mu \mathrm{g}$ $\mathrm{NaCl} / \mathrm{cm}^{2}$.

(4) Boards with Au coating have smaller surface contamination, than identical boards without Au coating. Phosphorous content in the group of boards with Au coating has not serious influence on surface contamination.

\section{Acknowledgments}

The work has been carried out within research project "Improving the reliability of lead-free soldered joints in electronic packages", No. WND-POIG.01.03.01-00-103/09, financed by the EC structural funds and the Ministry of Science and Higher Education of Poland.

\section{Open Access}

This article is distributed under the terms of the Creative Commons Attribution License which permits any use, distribution, and reproduction in any medium, provided the original author(s) and the source are credited. 


\section{References}

1. J. Felba, Electronic Assembly, Wroclaw University of Technology Publishing House, Wroclaw, 2010

2. K. Bukat and H. Hackiewicz, Pb Free Soldering, BTC, Warsaw, 2007

3. K.H. Kim, J. Yu, and J.K. Kim, A Corrosion Coupe Experiment Reproducing the Black Pad Phenomenon Found After the Electroless Nickel Immersion Gold Process, Scr. Mater, 2010, 63, p $508-511$

4. R. Ramanuskas, A. Selskis, J. Juodkazyde, and V. Jasulaitiene, PCB Failure Analysis Related to the ENIG Black Pad Problem, Circuit World, 2013, 39(3), p 124-132

5. A. Siewiorek, A. Kudyba, N. Sobczak, M. Homa, Z. Huber, Z. Adamek, and J. Wojewoda-Budka, Effect of PCB Substrate Surface Finish and Flux on Solderability of Lead-Free SAC305 Alloy, J. Mater. Eng. Perform., 2013, 22(8), p 2247-2252

6. A. Siewiorek, A. Kudyba, M. Homa, and N. Sobczak, Effect of Surface Coating and Flux Type on the Solderability of PCB by
Lead-Free SAC305 Alloy, Trans. Found Res. Inst., 2012, 52(3), p 77-92

7. K. Bukat, Impurities Present in the Electronic Packages. Part 1: Ionic Impurities, Electronics, 1997, 11, p 5-8

8. MIL-P-288009 A, Printed Wiring Assemblies, 1981

9. T.J. Crawford, Step-by-Step SMT: The Next Step-Part 8-CleaningEven Though Assembly Conditions are Pristine, PCBs Remain Highly Vulnerable to Contamination from Many Sources, Surf. Mount Technol., 1995, 9(10), p 94-101

10. R.L. Iman et al., Design Rules a Must for Any Soldering Process, Surf. Mount Technol., 1996, 10(1), p 38-42

11. http://alphacpmd.com/Products/Liquid-Soldering-Flux/RF-800

12. User Manual Contamino CT100, Métronélec, France, 2010

13. R.M. Soble, Solvent Cleaning of Printed Wiring Assemblies, Insulation/Circuits, 1979, 5(2), p 25-29

14. M. Bacior, A. Siewiorek, A. Kudyba, and N. Sobczak, Ionic Contamination Tests on Printed Circuit Boards, Trans. Found. Res. Inst., 2013, 1, p 13-25 